\title{
Comprehensive Analysis on the Contribution of Winglets Fuel Based on Contrast Experiment
}

\author{
Yueli Sun ${ }^{1}$, Jingjie Chen ${ }^{1,2,3, *}$, Jincheng Cui, Qi Meng ${ }^{1}$ and Ziheng Xing ${ }^{4}$ \\ ${ }^{1}$ College of Electronic Information \& Automation, CAUC, China \\ ${ }^{2}$ Research Centre for Environment and Sustainable Development of CAAC, China \\ ${ }^{3}$ National Engineering Laboratory for Integrated Traffic Application Technology, China \\ ${ }^{4}$ China Southern Airlines, China \\ ${ }^{*}$ Corresponding author
}

\begin{abstract}
Previous research has shown that aviation fuel costs are the first major cost of air operations, and it is a key factor in profit and loss. In the operating environment under the combined effects of many factors, regardless of operating costs breakeven only to calculate the critical point of save fuel is challenging. This paper is to build fuel consumption mode based on comparative experiments and based on statistical analysis and BP neural network analysis. The model considers the main influence parameters including flight time, payload and so on. The results show that the installation of the winglets under given actual payload and flight time makes the fuel consumption increase.
\end{abstract}

Keywords- fuel consumption; winglet; statistical analysis; $B P$ neural network

\section{INTRODUCTION}

Due to energy shortages, the world's crude oil prices continue to rise, making the cost of aviation fuel costs more than $40 \%$ of the total cost of the aviation industry. In promoting the "conservation-oriented society" environment, emphasizing within the scope of the safe operation to saving the cost of fuel and use the most economical way to run is particularly necessary.

The installation of the winglets reduces the induced drag of the lift caused by the wing vortex. The test results show that the total resistance of the aircraft is reduced by $6.5 \%(15 \%$ reduction in induced resistance) due to the decrease in induced resistance. And the range is increased by $7.5 \%$. The winglets reduce the flow around the lift damage to improve the lift resistance ratio to reduce fuel consumption. The winglets reduced the thrust of the aircraft by $3 \%$, reduced by $3.4 \%$ during cruise, increased landing stability, reduced engine thrust, extended engine life, increased aircraft load and range, increased the value of the aircraft itself.

Although the performance and speed of climbing winglets have improved significantly after the installation of the winglets, the ability to resist large crosswind and the performance of turning are relatively poor. So it is not all the performance has been improved after the installation of the winglets. Winglet fuel-saving features only in a certain cruise altitude to play the more obvious [1]. At the same time, the installation of winglets cost and post-maintenance costs are relatively high. The total cost of conversion is about 1 million
US dollars, including modified package 72.5 thousand US dollars, labor costs 25 to 30 thousand US dollars, the aircraft parking period for two weeks and the total working hours about $7000 \sim 7500$ hours [2].

Here we will analysis the aircraft fuel changes before and after the installation of winglets.

\section{CONTRAST EXPERIMENTAL DESIGN}

\section{A. Influencing Factors of Aircraft Fuel Consumption}

Before comparing the fuel consumption of the aircraft, we must first clarify the factors that affect the fuel consumption of the aircraft. In general, the main influencing factors are aircraft weight, flight time, flight distance, flight speed, rate of climb, rate of descent, total air temperature, wind direction, wind speed and so on. According to statistics because the multicarrying weight of the aircraft per hour consumption of fuel equivalent to the extra weight of $3 \%$ to $4 \%$. The flight speed and flight height mainly affect the engine fuel consumption characteristics. The atmospheric environment directly affects the performance of the engine, and the engine fuel consumption at different temperatures is very different. The rate of climb and rate of descent mainly affect the climb phase and decline phase. [3-4]

\section{B. Data Characteristics}

This data is from a certain airline, mainly for the Boeing 737 series of $73 \mathrm{G}$ and 738 two models to the installation of the winglets before and after the fuel consumption data. The flight data for 2012 is the absence of the winglets (the following "2012" represents data without winglets). The flight data for 2014 is the installation of the winglets (below "2014" On behalf of the installation of the winglets). In this paper, mainly uses the flight distance, original deposit oil, new oil, retained oil, the number of adults, the number of children, the number of babies, mail weight, goods weight, baggage weight, and flight time. The flight distance is in kilometers $(\mathrm{km})$. The original deposit oil, new oil, retained oil, the number of adults, the number of children, the number of babies, mail weight, goods weight, baggage weight is in kilograms $(\mathrm{kg})$.

Calculate the fuel consumption $(\mathrm{kg})$, the actual payload (tons) and the total turnover of each flight. The total turnover is 
a comprehensive production indicator that reflects the movement and the transport distance, that is, passengers, goods, mail, and baggage in the air to achieve displacement. It is calculated by adult $75 \mathrm{~kg} /$ person, children $22.5 \mathrm{~kg} /$ person, baby $15 \mathrm{~kg} /$ person.

Fuel consumption $=$ original oil + new oil - retained oil

Actual payload $=$ (number of adults $\times 75+$ number of children $\times 22.5+$ number of babies $\times 15+$ mail weight + goods weight + baggage weight) $/ 1000$

Total turnover of transport $=$ flight distance $\times$ actual payload

Eliminate noise data. And noise data includes fuel consumption of 0 and actual payload less than 2 tons.

\section{ANALYTICAL MethoD}

The analytical method is shown in Figure 1.

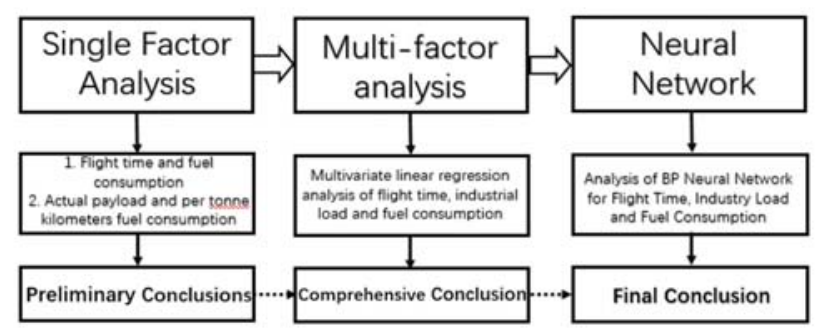

FIGURE I. ANALYTICAL METHOD

First, single factor analysis ignores the effects of other variables to analyze only the effects of individual variables on fuel consumption. Summarize the statistical method and lay the groundwork for the next analysis.

The per ton kilometer fuel consumption as fuel consumption performance indicators, which is defined as the aircraft transport 1 ton of cargo flying $1 \mathrm{~km}$ of fuel consumption is a transport industry to calculate the cost of transport methods.

per ton kilometers fuel consumption=(fuel consumption)/(Total turnover of transportation)

And then combine the various factors to carry out multifactor analysis to build fuel consumption model. The fuel consumption of the aircraft is $Y$ and the number of influencing factors is p. $x_{1}, x_{2}, \cdots, x_{p}$ represents different influencing factor. The multiple linear regression equation can be expressed as,

$$
Y=\beta_{0}+\beta_{1} x_{1}+\cdots+\beta_{p} x_{p}+\varepsilon
$$

where, $\varepsilon \sim N\left(0, \sigma^{2}\right), \beta_{0}, \beta_{1}, \cdots, \beta_{p}, \sigma^{2}$ is an unknown parameter independent of $x_{1}, x_{2}, \cdots, x_{p}$.

Introduce the square of the deviation.

$$
Q\left(\beta_{0}, \beta_{1}, \cdots, \beta_{p}\right)=\sum_{i=1}^{n}\left(y_{i}-\beta_{0}-\beta_{1} x_{1}-\cdots-\beta_{p} x_{p}\right)^{2}
$$

Since $Q\left(\beta_{0}, \beta_{1}, \beta_{2}, \cdots, \beta_{p}\right)$ is a nonnegative quadratic form of $\beta_{0}, \beta_{1}, \beta_{2}, \cdots, \beta_{p}$, we obtain a partial derivative of $\mathrm{Q}$ and let it be 0 . The establishment of multivariate and fuel consumption model introduced a comprehensive conclusion.

Finally, the BP neural network with multi-layer feedforward is used to fuzzify the strict expression of the fuel consumption model of multi-factor analysis to make the fitting degree higher. BP neural network will affect the factors as input, fuel consumption as an output training. BP neural network forward signal transmission, reverse propagation error. The neuronal state of each layer affects only the neuronal state of the next layer. If the output layer is not expected to output, then transferred to the reverse propagation. According to the prediction error to adjust the network weights and threshold, so that BP neural network prediction output continues to approach the desired output.

BP neural network-based nonlinear function fitting algorithm can be divided into three steps: BP neural network construction, BP neural network training and BP neural network prediction, the algorithm flow shown in Figure 2.

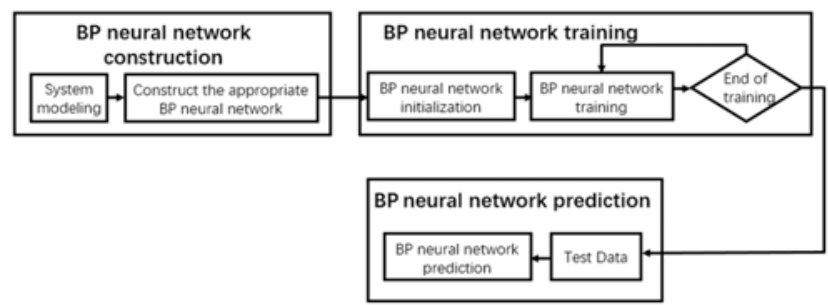

FIGURE II. ALGORITHM FLOW

\section{RESUlts ANALysis}

\section{A. Flight Time and Fuel Consumption}

The installation of the winglets before and after the flight time and fuel consumption of the scatter plot and scatter fitting trend line shown in Figure 3.

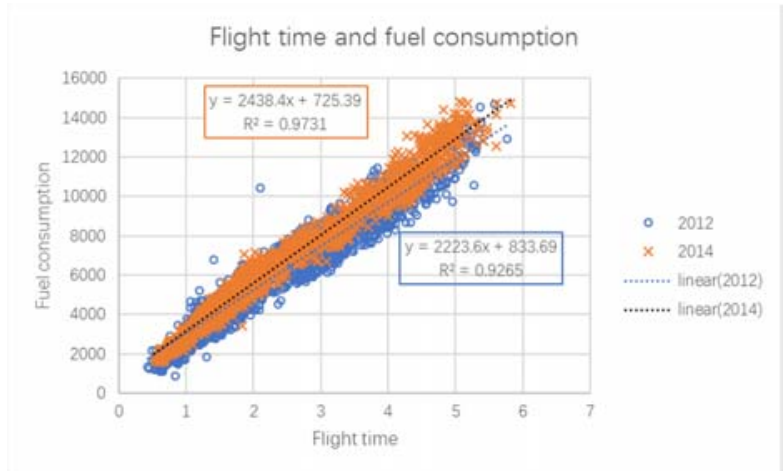

FIGURE III. SCATTER PLOT OF THE FLIGHT TIME AND FUEL CONSUMPTION BEFORE AND AFTER INSTALLATION OF THE WINGLETS 
From the figure we can see that with the increase in flight time, fuel consumption increased linearly. In the same flight time conditions, the 2014 fuel consumption slightly higher than 2012.

\section{B. Actual Payload and Per Ton Kilometer Fuel Consumption}

The installation of the winglets before and after the actual payload and per ton kilometer fuel consumption of the scatter plot and scatter fitting trend line shown in Figure 4.

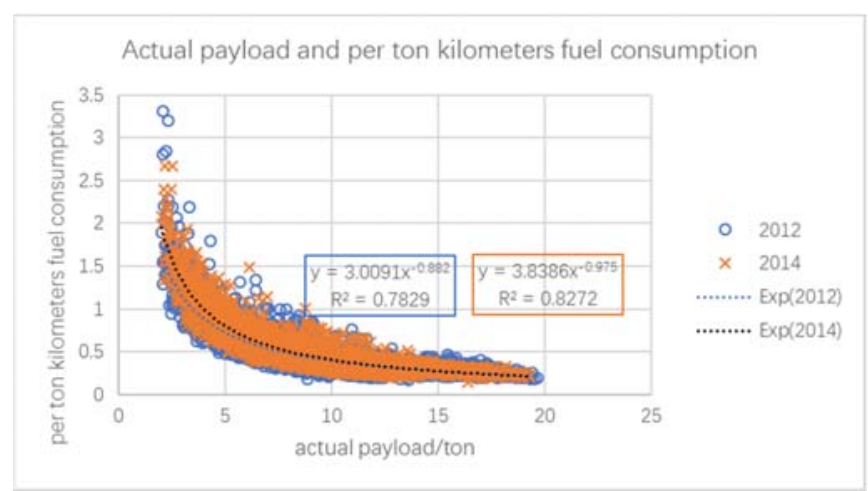

FIGURE IV. SCATTER PLOT OF THE ACTUAL PAYLOAD AND PER TON KILOMETERS FUEL CONSUMPTION BEFORE AND AFTER INSTALLATION OF THE WINGLETS

From the figure we can see that 2014 per ton kilometer fuel consumption is greater than 2012. With the actual payload increased per ton kilometer fuel consumption gradually decreased. Within 5 tons of decline in the trend of obvious. The actual payload is greater than 5 tons decline in the slowdown eventually stabilized.

\section{Regression Analysis}

To fuel consumption as the dependent variable. The actual payload and the flight time are independent variables. And perform multiple linear regression. The regression function is:

$$
\begin{gathered}
Z_{12}=-539.507+X_{12} \times 72.903+Y_{12} \times 2199.282 \\
Z_{14}=-302.038+X_{14} \times 39.554+Y_{14} \times 2388.31
\end{gathered}
$$

Where, $Z_{12}, X_{12}, Y_{12}$ is the fuel consumption, the actual payload and the flight time in 2012. $Z_{14}, X_{14}, Y_{14}$ is the fuel consumption, the actual payload and the flight time in 2014.

The three-dimensional diagram of the fuel consumption of the multiple regression model is shown in Figure 5.

It is clear from the figure that the fuel consumption in 2014 is higher than that in 2012, when the flight time and the actual payload are the same.

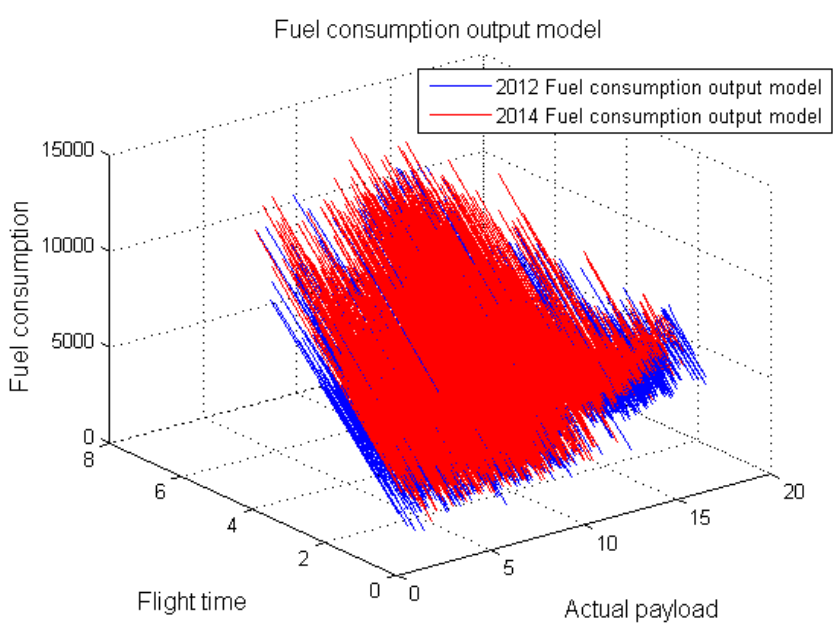

FIGURE V. MULTIPLE LINEAR REGRESSION FUEL CONSUMPTION THREE - DIMENSIONAL MAP

\section{BP Neural Network Analysis}

Using 2012 data as a training sample, where the input is the actual payload and the flight time, the output is the fuel consumption. Before the training, the data should be normalized by the maximum and minimum method to avoid the network prediction error caused by the difference of the input and output data level. Figure 6 shows the relative error of fuel consumption prediction for 2014 as a training sample for 2012 data.

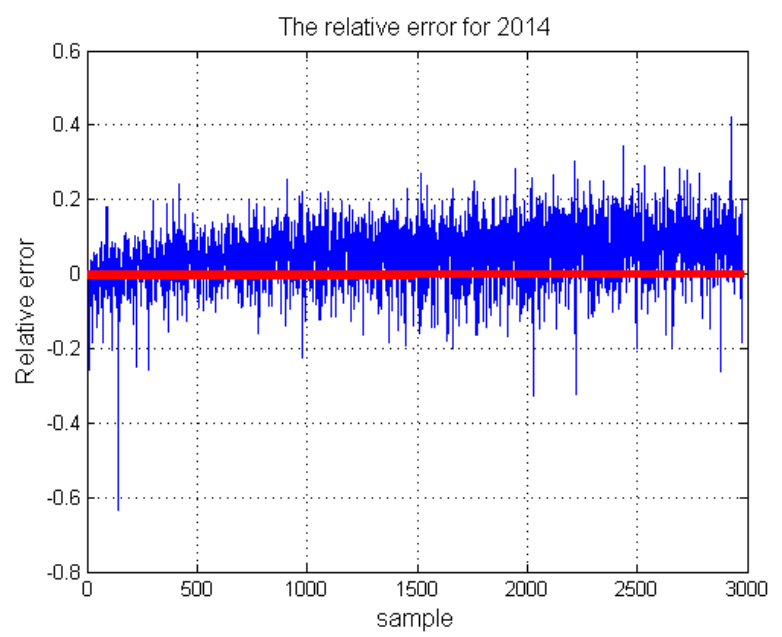

FIGURE VI. 2012 FOR TRAINING SAMPLES, THE RELATIVE ERROR OF FUEL CONSUMPTION FORECAST FOR 2014

By statistics, $76.9 \%$ of the data in the prediction error is greater than 0 . In this $38.4 \%$ of the data is greater than 0.1 . Less than 0 data in $89.0 \%$ of the data is greater than -0.1 . So using 2012 data to train samples to predict fuel consumption in 2014, the prediction is greater than the actual value, that is, high fuel consumption in 2014. 


\section{E. Results Test}

1) Actual payload and fuel consumption: Because multiple flights have similar flight times but fuel consumption fluctuates. Then select flight time of $60,120,180,240,300$ minute error \pm 2 minutes flight. Analyze the relationship between actual payload and fuel consumption to verify the above conclusions. (a), (b), (c), (d), (e) and (f) of Figure 7 are flight time 58 to 62, 118 to 122,178 to 182,238 to 242 minutes that the actual payload and fuel consumption scatter plot before and after installation of the winglets. Which is blue for 2012, orange for 2014.

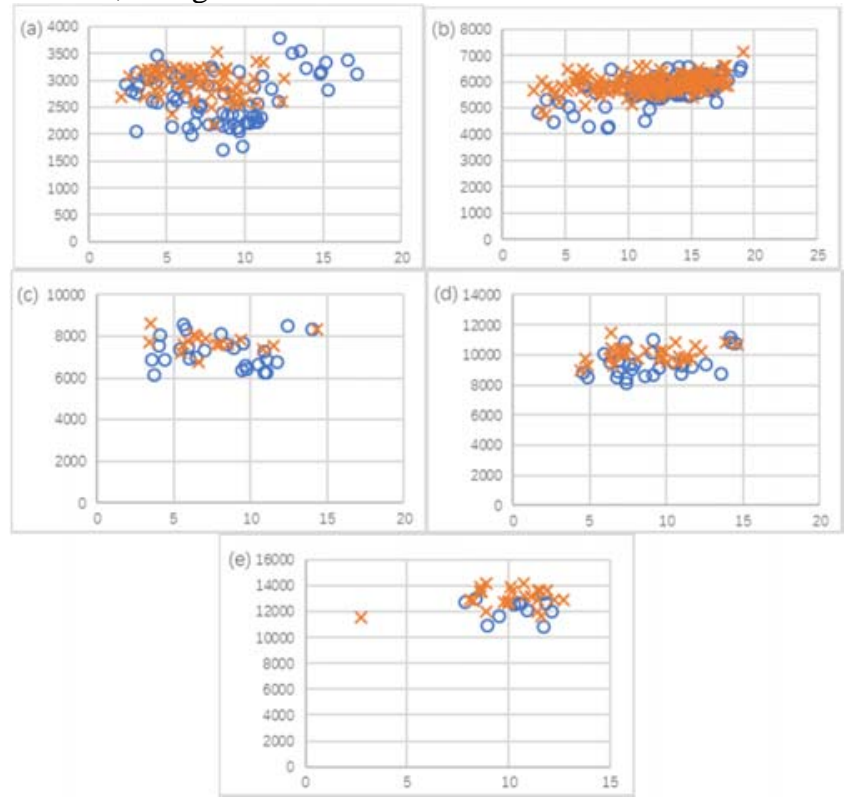

FIGURE VII. INSTALLATION WINGLETS BEFORE AND AFTER THE FLIGHT TIME FIXED, THE ACTUAL INDUSTRY LOAD AND FUEL CONSUMPTION SCATTER

As can be seen from the above chart, in the case of similar flight time and actual payload, the fuel consumption in 2014 is slightly higher than in 2012. Consistent with previous conclusions.

2) Flight time and per ton kilometers fuel consumption: Because multiple flights have similar actual payload but fuel consumption fluctuates. Then select actual payload of 4.5, 7 , $9.5,12,14.5,17$ ton error \pm 0.1 tons flight. Analyze the relationship between flight time and per ton kilometer fuel consumption to verify the above conclusions. (a), (b), (c), (d), (e) and (f) of Figure 8 are flight time 4.4 to 4.6, 6.9 to 7.1, 9.4 to $9.6,11.9$ to $12.1,14.4$ to $14.6,16.9$ to 17.1 tons that the flight time and per ton kilometer fuel consumption scatter plot before and after installation of the winglets. Which is blue for 2012, orange for 2014.

From the figure can be seen, with the increase in flight time per ton kilometer fuel consumption showed a downward trend. The actual payload contained below 12 tons basically meet the above conclusions. But at 14.5 tons and 17 tons with a conclusion deviation. And then select the actual payload greater than 14.5 tons of data for further analysis.

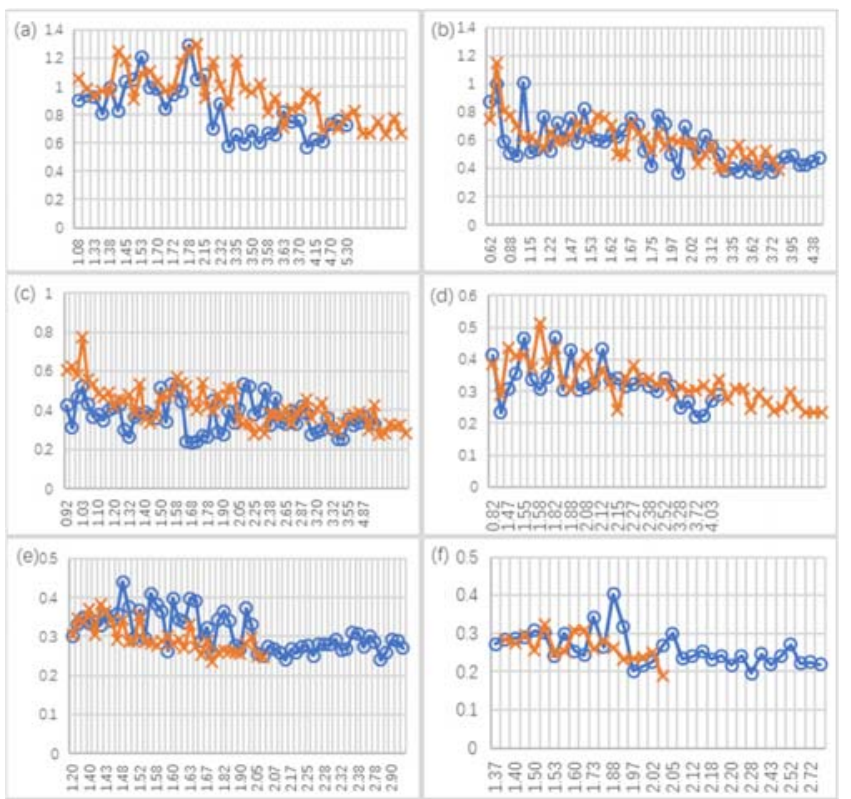

FIGURE VIII. INSTALLATION WINGLETS BEFORE AND AFTER THE PAYLOAD FIXED, THE FLIGHT TIME AND PER TON KILOMETERS FUEL CONSUMPTION SCATTER

Figure 7 is the actual payload greater than 14.5 tons, the installation of the winglets before and after the flight time and per ton kilometer fuel consumption line chart. Which is blue for 2012, orange for 2014.

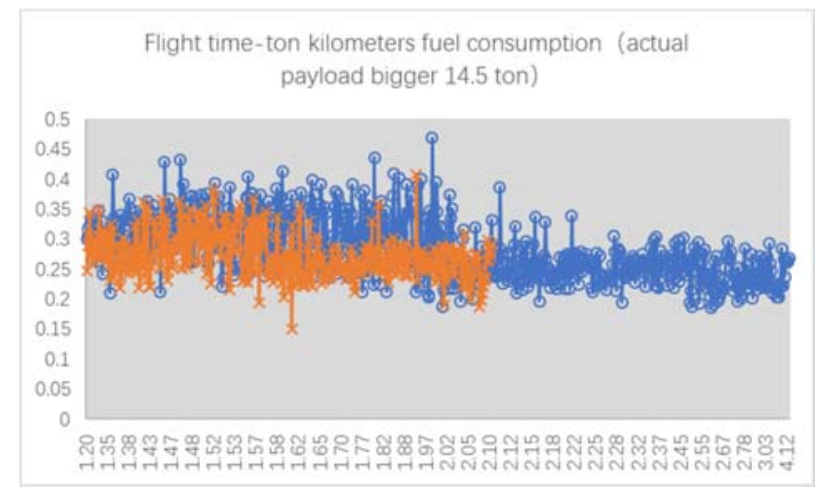

FIGURE IX. INSTALLATION WINGLETS BEFORE AND AFTER THE ACTUAL PAYLOAD IS GREATER THAN 14.5 TONS, FLIGHT TIME AND PER TON KILOMETERS FUEL CONSUMPTION LINE CHART

As can be seen from figure, the data for 2014 are mainly concentrated within 2 hours of flight time. And the flight time in 1.5 to 2 hours between 2014 per ton kilometer fuel consumption was significantly lower than in 2012. Then select the actual payload greater than 14.5 tons at the same time the flight time in 1.5 to 2 hours between the data to compare. At this point the main section of the distance of $1039 \mathrm{~km}$ from a certain segment of the data, only one segment of the data may be outside the segment of this segment is not representative of the impact. So that in line with the previous conclusions. 
3) Predict fuel consumption: The three-dimensional chart of the flight time, the actual payload and the actual fuel consumption is shown in Figure 10.

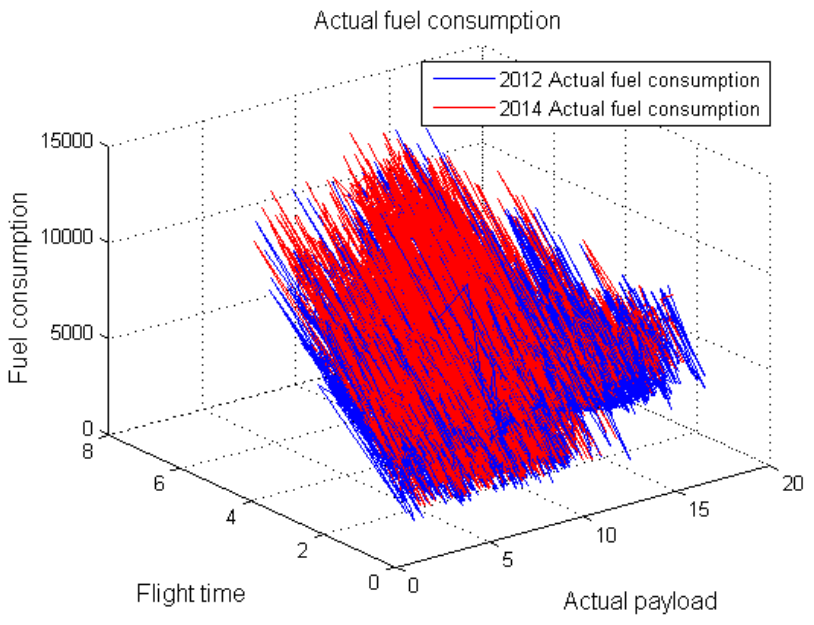

FIGURE X. THE THREE-DIMENSIONAL CHART OF THE FLIGHT TIME, THE ACTUAL PAYLOAD AND THE ACTUAL FUEL CONSUMPTION

Using 2014 data as a training sample with BP neural network to predict 2012 fuel consumption. The predicted relative error is shown in Figure 11.

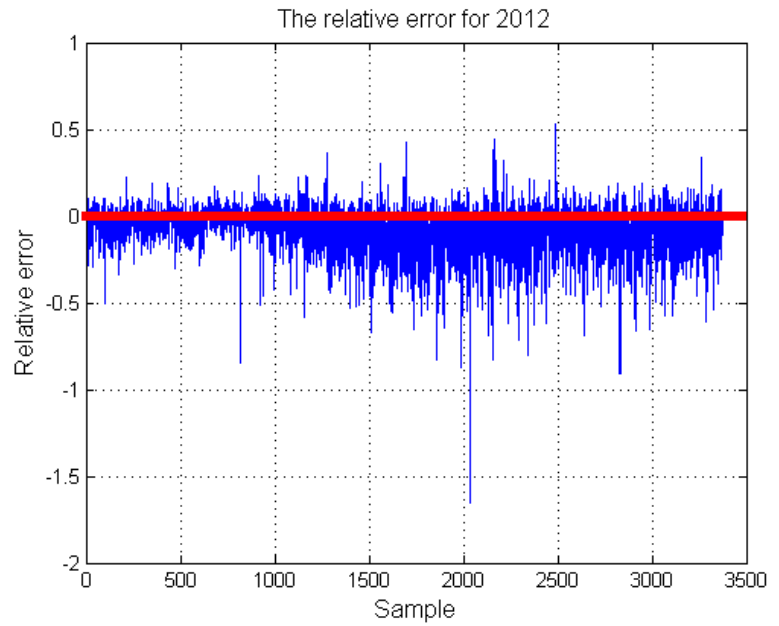

FIGURE XI. FUEL CONSUMPTION FORECAST ERROR OF 2012

From the figure we can see the actual data of the threedimensional map of the same flight time and actual payload conditions are still high fuel consumption in 2014.

BP neural network with 2014 data to predict fuel consumption in 2012. The relative error is a positive trend that the 2012 fuel consumption prediction is greater than the actual value. Consistent with the above conclusions.

\section{CONCLUSION}

Through statistical analysis, regression analysis, BP neural network prediction analysis of 2012 and 2014 data we have come to: a) Only to consider the flight time conditions, after the installation of winglets the increase in fuel consumption. In the range of \pm 2 minutes of flight time error, the fuel consumption increases with the increase of the payload. The installation of the winglets fuel consumption is higher than that of the wingless winglets.

b) Only to consider the payload, the installation of winglets fuel consumption increased. In the actual payload error within \pm 0.1 tons, per ton kilometers fuel consumption with the increase in flight time showed a downward trend.

c) At the same time consider the flight time and payload, the installation of winglets fuel consumption slightly higher.

In summary, the fuel consumption of the winglets is increasing without considering other factors taking into account both the flight time and the payload. But there are many factors that affect the aircraft fuel consumption. To further determine the impact of the installation of winglets on the need for further analysis.

\section{ACKNOWLEDGMENT}

This work is supported by National Key Technology Research and Development Program of China (Grant No. 2012BAC20B03), Special Program for Energy Saving and Emission Reduction of CAAC (Grant No. DPDSR0010) and Monitor for Energy Saving and Emission Reduction of CAAC (Grant No. DPDSR0061)

\section{REFERENCES}

[1] Jian Jiang, "Analysis of the advantages and disadvantages of wing tip winglets,” Jiangsu Airlines, no.1, pp. 25-26, 2012.

[2] Min Qiu, "Technical analysis of the winglet modification of the Boeing 767 aircraft," Aeronautical maintenance and engineering, pp. 73-75, April 2014.

[3] Donglin Zhao, Aircraft fuel consumption detection method and system design based on QAR data, Tianjin: Civil Aviation University of China, 2014.

[4] Jing Liu, Aircraft fuel estimation model based on flight data analysis, Nanjing: Nanjing University of Aeronautics and Astronautics, 2010.

[5] Jiawei Han, Micheline Kamber and Jian Pei, Concept and Technology of Data Mining, Beijing: Mechanical Industry Press, pp. 55-77, 2015.

[6] Feng Shi, Xiaochuan Wang, Lei Yu and Yang Li , MATLAB neural network 30 case analysis, Beijing: Beijing Aerospace University Press, pp. 11-19,2015.

[7] Enis T. Turgut, Marc A. Rosen, Relationship between fuel consumption and altitude for commercial aircraft during descent: Preliminary assessment with a genetic algorithm, Aerospace Science and Technology, Volume 17, Issue 1, March 2012, Pages 65-73, ISSN 1270-9638, http://dx.doi.org/10.1016/j.ast.2011.03.007. 